№ 34 - Enero

DOCUMENTOS DE TRABAJO IELAT

2012

La cláusula antisubcapitalización española: problemas actuales

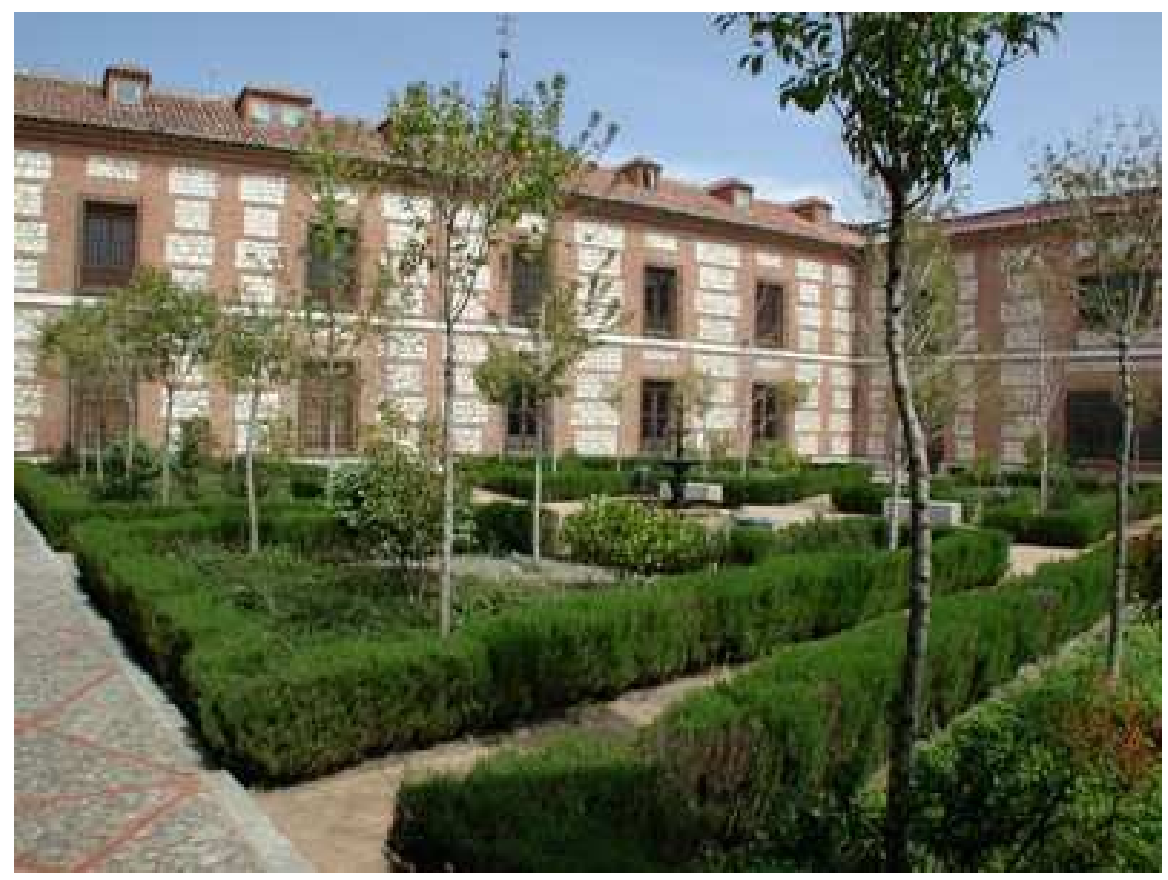

José Manuel Castro Arango 
La cláusula antisubcapitalización española: problemas actuales

José Manuel Castro Arango

Universidad 
Estos documentos de trabajo del IELAT están pensados para que tengan la mayor difusión posible y que, de esa forma, contribuyan al conocimiento y al intercambio de ideas. Se autoriza, por tanto, su reproducción, siempre que se cite la fuente y se realice sin ánimo de lucro. Los trabajos son responsabilidad de los autores y su contenido no representa necesariamente la opinión del IELAT. Están disponibles en la siguiente dirección: Http://www.ielat.es

Instituto de Estudios Latinoamericanos

Universidad de Alcalá

C/ Trinidad 1

Edificio Trinitarios

28801 Alcalá de Henares - Madrid

www.ielat.es

ielat@uah.es

Equipo de edición:

Ma. Cecilia Fuenmayor

Mercedes Martín Manzano

Eva Sanz Jara

Inmaculada Simón

Vanesa Ubeira Salim

Lorena Vásquez González

Guido Zack

Consultar normas de edición en el siguiente enlace: http://www.ielat.es/inicio/repositorio/Normas $\% 20$ Working\%20Paper.pdf

DERECHOS RESERVADOS CONFORME A LA LEY

Impreso y hecho en España

Printed and made in Spain

ISSN: 1989-8819

\section{Consejo Editorial}

UAH

Diego Azqueta

Concepción Carrasco

Isabel Garrido

Carlos Jiménez Piernas

Manuel Lucas Durán

Diego Luzón Peña

José Luis Machinea

Pedro Pérez Herrero

Daniel Sotelsek Salem

\section{Unión Europea}

Sergio Costa (Instituto de Estudios Latinoamericanos, Universidad Libre de Berlín, Alemania)

Ana María Da Costa Toscano (Centro de Estudios Latinoamericanos, Universidad Fernando Pessoa, Porto, Portugal)

Georges Couffignal (Institute des Haute Etudes de L'Amérique Latine, Paris, Francia)

Leigh Payne (Latin American Centre and Brasilian Studies Programme, Oxford, Gran Bretaña)

\section{América Latina y EEUU}

Juan Ramón de la Fuente (Universidad Nacional Autónoma de México, México)

Eduardo Cavieres (Pontificia Universidad Católica de Valparaíso, Chile)

Eli Diniz (Universidad Federal de Río de Janeiro, Brasil)

Carlos Marichal (El Colegio de México, México)

Armando Martínez Garnica (Universidad Industrial de Santander, Bucaramanga, Colombia)

Marcos Neder (Trench, Rossi e Watanabe Advogados Sao Paulo, Brasil)

Peter Smith (Universidad de California, San Diego, EEUU)

Francisco Cueto (Facultad Latinoamericana de Ciencias Sociales -FLACSO-, República Dominicana) 


\title{
La cláusula antisubcapitalización española: problemas actuales ${ }^{1}$
}

\author{
José Manuel Castro Arango* \\ Universidad Externado de Colombia
}

\section{Resumen}

Este trabajo analiza el artículo 20 del Texto Refundido de la Ley de Impuesto de Sociedades (TRLIS) que restringe la subcapitalización de entidades residentes. Se describen los principales problemas que generan los elementos objetivos y subjetivos de la norma, así como los efectos que conlleva para la entidad residente y la no residente, y su dudosa naturaleza jurídica. La perspectiva crítica con que se aborda el tema permitirá determinar que la norma tiene un estrecho ámbito de aplicación y, en consecuencia, que existen situaciones no cubiertas, en la cuales la elusión fiscal no podrá ser solucionada.

\section{Palabras clave:}

Subcapitalización, elusión fiscal, dividendos, intereses, financiación empresarial.

\section{Abstract}

This paper analyses the article 20 of the Consolidated Text of the Corporate Income Tax Law where the thin capitalization of resident entities is limited. This essay describes the art. 20's main problems in the object and subject requirements, its effects on resident and non-resident entities, and its non clear juridical nature. The critic perspective adopted in this paper concludes that this rule applies just in one narrow group of situations and consequently, there are normative gaps where tax avoidance could not be solved.

\section{Keywords}

Thin capitalization, tax avoidance, dividends, interest, corporate finance.

\footnotetext{
${ }^{1}$ Agradezco a la Universidad Externado de Colombia quien patrocinó esta investigación y al Profesor Dr. Manuel Lucas Durán por sus aportes a este trabajo.

* Docente investigador de la Universidad Externado de Colombia. Magister en Derecho de la Empresa del CIFF (2010), Magíster Universitario en Derecho de la UAH (2011) y Especialista en Derecho Comercial del Externado (2009). Contacto: jose.castro@uexternado.edu.co
} 


\section{INTRODUCCIÓN}

\section{PRIMERA PARTE: LA SUBCAPITALIZACIÓN: PROBLEMAS Y SOLUCIONES}

\section{EL CONCEPTO DE SUBCAPITALIZACIÓN}

La financiación empresarial se clasifica en dos grandes categorías: los fondos propios (equity) y el endeudamiento (debt). La remuneración de los primeros, por lo general, se denomina dividendos y la de los segundos intereses. El tratamiento dado por las normas contables, mercantiles y tributarias a la financiación interna y externa es distinta y tiende a favorecer la financiación externa frente a la interna. Ello sumado a la fungibilidad existente entre ambos, conlleva a que los empresarios suelan escoger entre una $u$ otra financiación de acuerdo a sus intereses y persiguiendo la mayor rentabilidad a menor riesgo. Por lo general, el análisis empresarial lleva a que los recursos se den a la empresa a través de endeudamiento y no de fondos propios, generando subcapitalización.

La subcapitalización ocurre cuando existe una proporción entre fondos propios y endeudamiento que excede de los rangos considerados normales. La fijación del grado de "normalidad" en esta proporción resulta particularmente compleja, pues debe atender a las razones por las cuales se pretende corregir la falla de mercado generada. La subcapitalización es un fenómeno distinto pero relacionado con el de la financiación híbrida donde los elementos diferenciadores entre una y otra categoría se desdibujan; por lo general, es una financiación con apariencia legal de externa -endeudamientopero que involucra una participación en el riesgo empresarial, criterio éste, usualmente atado a la financiación interna -fondos propios-.

\section{EL PROBLEMA TRAS LA SUBCAPITALIZACIÓN}

El Derecho Mercantil, al reconocer tal fungibilidad, reacciona con normas que buscan proteger a los acreedores ${ }^{2}$. Las normas contables persiguen reconocer las operaciones de la forma más transparente y acorde con la realidad económica. El Derecho Tributario por su parte busca fijar la base imponible del Impuesto de Sociedades de la forma que más se adecue al principio constitucional de capacidad contributiva. Son muchas las perspectivas que derivan de la finalidad fiscal, pues, por ejemplo, de un lado puede buscarse que la remuneración por la financiación se haga a precios de mercado - precios de transferencia-, y de otro, que no se aprovechen las ventajas fiscales de una u otra categoría como los tipos de retención o la deducibilidad de los gastos por intereses.

Una perspectiva común de la subcapitalización en los varios ordenamientos es la que ve en estas situaciones un problema de traslado de bases imponibles de los

\footnotetext{
2 Paz-Ares Rodríguez, Cándido, "La Infracapitalización. Una Aproximación Contractual”, en: Revista Derecho de Sociedades, núm. Extraordinario, 2004, p. 253-269.
} 
impuestos sobre la renta de una entidad a otra. Se entiende que los grados anormales de financiación con deuda implica una distorsión en la determinación de las bases imponibles, ya que lo que constituye gasto en una entidad, pasa a convertirse en ingreso de otra entidad que podrá estar sujeta a un régimen impositivo más favorable (menor tipo, mayores gastos deducibles, etc.) o tener pérdidas por compensar.

Otros efectos en materia tributaria son por ejemplo que en España las aportaciones societarias se encuentran gravadas por el impuesto de transmisiones patrimoniales y actos jurídicos documentados (En adelante ITPAJD), mientras que los préstamos no ${ }^{3}$. Además, en los impuestos sobre la renta y el patrimonio, la distinción entre deuda y capital tiene un importante efecto en algunos ordenamientos. Como ya se ha indicado, en lo que concierne a la entidad prestamista o aportante, la financiación a través de deuda le generará intereses, mientras que la financiación a través de capital genera dividendos, los primeros no sometidos a doble imposición económica, mientras que los segundos, salvo medidas concretas, pueden soportarla ${ }^{4}$. Además, pueden tener un tratamiento distinto en las retenciones practicadas por el ordenamiento interno aunque esto no ocurre en España, sí es un efecto importante en otros ordenamientos como el colombiano. Ello tendría una especial relevancia cuando los pagos se realizan en un entorno internacional, dado que los distintos Convenios de Doble Imposición (En adelante CDI) reconocen tributaciones en la fuente normalmente diferenciadas para los intereses o para los dividendos. Respecto de la entidad financiada, los intereses son un gasto deducible mientras que los dividendos no, pues se pagan después de calcular el beneficio de la entidad que los distribuye y una vez

\footnotetext{
${ }^{3}$ Así pues, el art. 19.1.1 del Real Decreto Legislativo 1/1993, de 24 de septiembre, por el que se aprueba el Texto Refundido de la Ley del Impuesto sobre Transmisiones Patrimoniales y Actos Jurídicos Documentados considera operación sujeta a la modalidad de Operaciones Societarias la constitución de sociedades y el aumento de capital de las mismas. Asimismo, el art. 7.1.b) del mismo texto legal considera transmisiones patrimoniales sujetas los préstamos, si bien el art. 45.I.B.15 de dicho texto legal los declara exentos. Ello no obstante, es preciso tener en cuenta que a partir del Real Decreto-Ley 13/2010 de 3 de diciembre están exentas también las constituciones y aumentos de capital de sociedades mercantiles (art. 43.I.B.11 del texto citado).

${ }^{4}$ La sobre imposición jurídica internacional ha sido definida como el solapamiento de dos o más jurisdicciones tributarias (sujetos activos), con impuestos idénticos o similares sobre una misma renta, en un mismo periodo gravable y sobre un mismo contribuyente. Nótese que la definición requiere cuatro identidades: impuestos semejantes (un elemento objetivo), un mismo hecho (elemento material), un mismo periodo gravable (elemento temporal) y un mismo contribuyente (elemento personal). Xavier agrega que es fundamental que exista un concurso de pretensiones (Anspruchskonkurrenz) que consisten en los créditos tributarios que de ellos deriva. También existe una sobre imposición económica que sería aquella que reúne todos los elementos de la jurídica menos el subjetivo. El Modelo de Convenio de Doble Imposición (en adelante MCOCDE) en el comentario 1 de la introducción se refiere a la doble imposición jurídica como la que genera efectos nocivos para el libre intercambio de bienes, servicios y el movimiento de capitales, tecnología y personas. De ahí que la lucha se haya centrado en la jurídica, aunque ciertamente en ocasiones también se busca eliminar la económica. Xavier, Alberto, Derecho Tributario Internacional. Conceptos Fundamentales, Editorial Ábaco de Rodolfo de Palma, Buenos Aires, 2005, p. 55. La teoría de las cuatro identidades es reconocida de manera general por la doctrina e incluso por el MCOCDE en el comentario 1 de la introducción. Cfr. Rocha, Sergio André, Interpretation of Double Taxation Conventions. General Theory and Brazilian Perspective, Kluwer Law International BV, The Hague, 2009, p. 152. Rohatgi, Roy. Idrovo, Juan Manuel (Trad.), Principios Básicos de Tributación Internacional, 1ạ edición en español, Legis, Bogotá D.C., 2008, p. xxxviii.
} 
esta ha pagado impuestos. En Colombia, el capital aumenta el resultado de patrimonio líquido lo cual trae como efecto el aumento de la base de renta presuntiva y del impuesto sobre el patrimonio ${ }^{5}$. En España, el impuesto sobre el patrimonio se encuentra en la actualidad bonificado al $100 \%$, con lo cual este último efecto no tiene mayor relevancia por el momento, aunque en vista de la intención reciente del Gobierno por restablecerlo también podría afectarlo.

Ahora bien, en materia internacional, financiar con deuda supondrá, de hecho, la posibilidad de trasladar la tributación de un Estado a otro. En efecto, la entidad financiada no tributará en el Estado de su residencia por los intereses pagados ya que reducirá sus beneficios con los gastos deducibles por los citados intereses. Los intereses podrán o no, tener una retención en la fuente (withholding tax) en dicho Estado, considerando el ordenamiento interno, los CDI y el Derecho Comunitario. Para el Estado de residencia del prestamista, las rentas obtenidas por los intereses cobrados serán un ingreso gravable por el criterio de renta mundial en la medida que aumentará el beneficio computado en este último Estado ${ }^{6}$.

\section{LA SUBCAPITALIZACIÓN Y LAS MEDIDAS ANTIELUSIÓN}

Sobre esta base, se ha buscado atacar la subcapitalización a través de medidas antielusión generales (General Anti-Avoidance Rules, por su acrónimo en inglés $\mathrm{GAAR}^{\prime} \mathrm{s}^{7}$ ). La subcapitalización no debe ser satanizada, por tanto, no debe ser

\footnotetext{
${ }^{5}$ En Colombia la base imponible del Impuesto de Renta se determina bien con un sistema de depuración fiscal de los ingresos, al cual se le restan los costos y deducciones, ello arroja el un monto que no podrá ser inferior a un rendimiento presunto (su naturaleza parece la de una ficción legal) que consiste en el $3 \%$ del patrimonio. La cuantificación del Patrimonio se obtiene de restar los pasivos exigibles a los activos. De ahí que la financiación con deuda genere una menor base imponible presunta en el Impuesto de Renta. Además, el Impuesto al Patrimonio también se afecta pues la cuantificación de la base imponible en este tributo resulta también del cálculo de los activos menos los pasivos. Vid. República de Colombia, Estatuto Tributario (adoptado mediante Decreto 624 DE 1989), Arts. 188 y ss. Arts. 292 y ss. Arts. 261 y ss. En especial el art. $266 \mathrm{ET}$ indica "El patrimonio líquido gravable se determina restando del patrimonio bruto poseído por el contribuyente en el último día del año o período gravable el monto de las deudas a cargo del mismo, vigentes en esa fecha." El impuesto al patrimonio en Colombia, a diferencia de España antes de ser exento, afecta tanto a sociedades como a personas físicas, de ahí la relevancia que presta el tema de la subcapitalización a efectos de la determinación de este impuesto.

${ }^{6}$ Makhmudova, Kamila. "Conflicts of Qualification and Thin Capitalization Rules", en, Burgstaller, Eva y Haslinger, Katharina (Eds.), Conflicts of Qualification in Tax Treaty Law, LINDE, Viena, 2007, p. 251-267. Sostiene esta autora que una de las más simples vías que tienen las compañías multinacionales para reducir su factura tributaria es financiar a sus filiales ubicadas en jurisdicciones de alta imposición con créditos otorgados por los accionistas o miembros del grupo en jurisdicciones con bajos tipos de impuestos. Así, la filial reduce su tipo efectivo de impuesto sobre beneficios empresariales por medio de la deducción de intereses y el prestamista recibe intereses gravables en el Estado de menor imposición. De este modo, se transfieren efectivamente los beneficios gravables de una jurisdicción de alta imposición a una de baja imposición. Cfr. p. 253.

${ }^{7}$ Para describir las GAAR's es menester empezar por decir que no son principios interpretativos, pues la interpretación está restringida al sentido propio de las palabras, mientras que las cláusulas generales anti-elusión conllevan a una calificación fiscal que excede el sentido propio de las palabras, buscando determinar la naturaleza jurídico-tributaria meramente formal de la operación, pudiendo desconocer la naturaleza jurídico privada y aparente de una operación. De manera general en España se considera que
} 
considerada per se, una simulación en los términos del art. 16 Ley General Tributaria (En adelante LGT), ni un conflicto en la aplicación en la aplicación de la norma tributaria al que se refiere el art. 15 LGT. Ello no quiere decir que, si en cada caso en concreto se evidencian los elementos que dan lugar a la aplicación de estas normas generales, no puedan desconocerse las operaciones que dan lugar a la subcapitalización a los efectos netamente tributarios. Otras cláusulas generales como el principio de independencia ( $\mathrm{arm}$ 's lenght) o el principio mercantil de contabilización de acuerdo con la realidad económica sobre la jurídica, también podrían permitir una recalificación del endeudamiento en fondos propios, no obstante su aplicación no está fuera de dudas. Sobre este último punto, debe resaltarse que la cuestión del alcance de la aplicación de los criterios de calificación contable a la materia tributaria es un punto controvertido en la doctrina española ${ }^{8}$.

Por las dificultades que envuelve probar la existencia de un conflicto en la aplicación de la norma tributaria, la simulación, o cualquier cláusula general antielusión, o la búsqueda de comparables para determinar si la situación respeta el principio de independencia, se ha planteado establecer cláusulas específicas que eviten la subcapitalización ${ }^{9}$.

Algunas cláusulas especiales antielusión corrigen, a efectos fiscales, las situaciones de subcapitalización, unas indirectamente, como ocurre con la Transparencia Fiscal Internacional, y otras directamente como lo hace, en la legislación española, el art. 20 Texto Refundido de la Ley de Impuesto de Sociedades (En adelante TRLIS) que es una cláusula específica para atacar la subcapitalización. Es precisamente esta norma la que analizaremos, no sin antes describir un poco las normas antisubcapitalización adoptadas en otros Estados.

\section{LAS CLÁUSULAS ANTISUBCAPITALIZACIÓN}

Las cláusulas anti subcapitalización se configuran con diversos matices en el Derecho Comparado, tal como destaca $\mathrm{PLITZ}^{10}$ y que reflejaremos muy brevemente en este apartado.

\footnotetext{
la principal norma general anti-elusión es el artículo 15 LGT sobre el conflicto en la aplicación de la norma tributaria, si bien este artículo se relaciona con el artículo 13 referido a la calificación de los hechos de acuerdo con su naturaleza jurídica. También puede considerarse una clausula general antielusión el artículo 16 LGT sobre la simulación.

${ }^{8}$ Sanz Gadea, Eduardo, Medidas Anti-Elusión Fiscal, Documento IEF 08/09, Instituto de Estudios Fiscales, Madrid, $2009 . \quad$ Disponible en: http://www.ief.es/documentos/recursos/publicaciones/documentos trabajo/2009 08.pdf p. 27-31. Báez Moreno, Andrés, Normas Contables e Impuesto sobre Sociedades, Aranzadi, Cizur Menor, 2005.

${ }^{9}$ También se utilizan otras técnicas para evitar otras elusiones relacionadas del juego entre capital y deuda que no son objeto de este estudio. Para mayor profundidad sobre tema consultar. Zielke, Rainer, "Shareholder Debt Financing and Double Taxation in the OECD: An Empirical Survey with Recomendations for the Further Development of the OECD Model and International Tax Planning", en: Intertax, núm. 38, 2010. p. 62-92.

${ }^{10}$ Sobre los distintos sistemas se puede consultar: Plitz, Detlev J., "General Report", en: AA.VV., Cahiers de Droit Fiscal International: International 1996, Aspects of Thin Capitalization, Congreso de Suiza, vol.
} 
El Informe de la OCDE sobre subcapitalización y fiscalidad de artistas y deportistas de $1987^{11}$ indica que hay dos tipos de medidas contra la subcapitalización: el sistema subjetivo, que atiende a las condiciones especiales de cada caso, buscando la comparabilidad y con ello el respeto al principio de independencia ${ }^{12}$; y, el sistema objetivo o de ratios fijas, que determina topes de endeudamiento. Esta organización internacional recomienda el subjetivo por ser más compatible con el principio de independencia, pero aclara que si se toma el objetivo debe permitirse probar las circunstancias especiales, de forma que se dé un respeto a dicho principio y no exista la posibilidad de disimular ${ }^{13}$.

Las cláusulas anti-subcapitalización incorporadas en los sistemas tributarios suelen tener uno de los siguientes efectos: a) negar la deducibilidad de los intereses que superen cierta ratio. b) reclasificar la deuda en capital y, en consecuencia, tratar los intereses como dividendos, o, c) tratar el diferencial como dividendos sin recalificar el préstamo en capital. En todo caso, estos son ajustes extracontables que tienen un impacto únicamente fiscal.

Los estados suelen escoger uno de dos factores determinantes: un excesivo nivel de endeudamiento que conlleva una baja proporción de capital sobre las deudas o, por otro lado, un alto porcentaje de gastos en intereses respecto de los ingresos ${ }^{14}$. A veces, estos factores se atan a la existencia de vinculación económica ${ }^{15}$ y en otras ocasiones se aplican de manera genérica a todos los créditos sin diferenciar a quien otorga el financiamiento ${ }^{16}$. De igual manera, lo usual es calcular la ratio de endeudamiento por cada accionista o sujeto individualmente. Las normas anti-subcapitalización suelen aplicarse también en operaciones back to back loans donde se utiliza un financiamiento de un tercer sujeto pero el mismo es garantizado por un vinculado con la financiada ${ }^{17}$. La ratio de endeudamiento puede ser fija y estricta o flexible y

81b, 1996, p. 83-139, disponible en www.ibfd.org (IBFD - tax research platform). p. 105 y ss. Vid. Asimismo OECD, Committee of Fiscal Affairs. Issues in International Taxation No. 2 -Thin Capitalization and Taxation of Entertainers, Artistes and Sportmen, París, 1987, p- 105 y ss. (En adelante Informe OCDE 1987 sobre subcapitalización)

${ }^{11}$ Informe OCDE 1987 sobre subcapitalización.

${ }^{12}$ Así por ejemplo, la existencia de deudas bastante altas, financiaciones a largo plazo o sin plazo, la existencia de créditos participativos o préstamos convertibles en acciones, divergencia entre el tipo convenido y el de mercado, etc.

${ }^{13}$ Informe OCDE 1987 sobre subcapitalización.

${ }^{14}$ Ejemplo de esto es la legislación italiana que establece que los gastos de intereses que excedan del $30 \%$ del índice earnings before interest, taxes EBITDA en cada período no serán deducibles en dicho ejercicio fiscal, pero podrán trasladarse indefinidamente a los siguientes años siempre que se respete el mismo límite. Palombo, Maria Eugenia, "Italy", en: International Transfer Pricing Journal, vol. 15, núm. 6, IBFD, Amsterdam, 2008, p. 318-320.

${ }^{15}$ Como existe en España y Alemania.

${ }^{16}$ Como ocurre en Rumania, Bulgaria, Hungría y Nueva Zelanda. Makmudova, Kamila, "Conflicts of Qualification and Thin Capitalization Rules", op. cit., p. 259. En estos casos, la subcapitalización se analiza sin atender a que se trate de entidades vinculadas, de tal forma se evaluará el endeudamiento con cualquier sujeto.

17 Ibidem p. 257. Los créditos back to back, como veremos más adelante al hablar de endeudamiento indirecto, supone una intermediación por parte de un tercero en la operación. 
subjetiva: en el primer caso se aplica a todos los contribuyentes sin distinción y en el segundo se hacen ciertas excepciones y consideraciones a los casos concretos ${ }^{18}$.

\section{SEGUNDA PARTE: LA INOPERANCIA DE LA CLÁUSULA ANTISUBCAPITALIZACIÓN ESPAÑOLA}

Actualmente la subcapitalización está regulada en el art. 20 del Texto Refundido de la Ley de Impuesto sobre sociedades adoptado mediante Real Decreto Legislativo 4/2004, de 5 de marzo, (en adelante TRIS). El texto vigente reza:

\section{“Art. 20 Subcapitalización}

1. Cuando el endeudamiento neto remunerado, directo o indirecto, de una entidad, excluidas las entidades financieras, con otra $u$ otras personas o entidades no residentes en territorio español con las que esté vinculada, exceda del resultado de aplicar el coeficiente 3 a la cifra del capital fiscal, los intereses devengados que correspondan al exceso tendrán la consideración de dividendos.

2. Para la aplicación de lo establecido en el apartado anterior, tanto el endeudamiento neto remunerado como el capital fiscal se reducirán a su estado medio a lo largo del período impositivo.

Se entenderá por capital fiscal el importe de los fondos propios de la entidad, no incluyéndose el resultado del ejercicio.

3. Los sujetos pasivos podrán someter a la Administración tributaria, en los términos del art. 16.7 de esta ley, una propuesta para la aplicación de un coeficiente distinto del establecido en el apartado 1. La propuesta se fundamentará en el endeudamiento que el sujeto pasivo hubiese podido obtener en condiciones normales de mercado de personas o entidades no vinculadas.

Lo previsto en este apartado no será de aplicación a las operaciones efectuadas con o por personas o entidades residentes en países o territorios considerados como paraísos fiscales.

4. Lo previsto en este art. no será de aplicación cuando la entidad vinculada no residente en territorio español sea residente en otro Estado miembro de la Unión Europea, salvo que resida en un territorio calificado reglamentariamente como paraíso fiscal."

La normativa citada puede ser estudiada a partir de un ámbito objetivo y subjetivo de aplicación, sus efectos y naturaleza jurídica tal como veremos más adelante. Argumentaremos a continuación como la cláusula en comento sólo se aplica a un grupo reducido de situaciones de subcapitalización.

\footnotetext{
${ }^{18}$ Ibidem., p. 257. Informe OCDE 1987 sobre subcapitalización, Sec. II. Para. 25.
} 


\section{1. ÁMBITO SUBJETIVO DE APLICACIÓN}

El ámbito subjetivo de aplicación de la cláusula anti-subcapitalización comprende las entidades residentes excluidas las entidades financieras, y a las operaciones de financiamiento directas e indirectas con personas o entidades no residentes en territorio español con las que esté vinculada (art. 16.3 TRLIS), excluyéndose de estas últimas las residentes en un Estado de la Unión Europea, salvo que éste sea considerado un paraíso fiscal.

Los elementos subjetivos del artículo 20 TRLIS son los siguientes:

Una "entidad residente no financiera" que recibe una financiación y una "entidad no residente" que la proporciona, existiendo vinculación económica entre ambas en los términos del art. 16 TRLIS. La condición de residente o no residente se determina de acuerdo con los arts. 9 y 10 de la Ley de Impuesto de Renta de Personas Físicas (LIRPF), 8 TRLIS y 6 del Texto Refundido de la Ley de Impuesto de Renta de no Residentes (TRLIRNR). Por entidades, para el caso de las residentes, debe entenderse personas jurídicas a las que se les aplique el IS y los Establecimientos Permanentes (En adelante EP) sujetos a determinación de la base imponible con las reglas de IS. Para el caso de las no residentes, esto es, quienes proveen la financiación, serán entidades, cualquier obligado tributario, sin importar si es una persona física, jurídica o una entidad sin personalidad jurídica.

Se ha discutido en la Doctrina si la financiación que reciben los EP configurados en España, por parte de su oficina o casa central, queda o no cubierta por la norma antisubcapitalización.

Los EP son un aspecto controvertido pues se trata de un criterio de conexión independiente de la residencia, y el art. 20 TRLIS cualifica a los sujetos de acuerdo a su residencia en el territorio español. Para Cordón y Gutiérrez ${ }^{19}$ la existencia del artículo 18.1.c TRLIRNR hace inaplicable el art. 20 del TRLIS por ser norma especial. Sin embargo, hemos evidenciado que las operaciones de financiación recibidas por el EP sito en España por otra entidad vinculada no residente -distinta de su casa central u otros EP de la misma-, sí quedarían comprendidas dentro del ámbito subjetivo del art. 20 TRLIS. Un segundo supuesto que se ha discutido es si el artículo 20 TRLIS es aplicable a operaciones de financiación entre EP radicados en España. Hemos concluido que los EP de entidades extranjeras sitos en España que reciben una financiación de su casa central, no están sujetos al art. 20 TRLIS por ser de aplicación el art. 18.1.c TRLIRNR. No obstante, si la financiación la prestan otras entidades vinculadas residentes en el exterior, distinta de su casa central u otros EP de la misma, el art. 18.1.c TRLIRNR no resulta aplicable y abre la puerta al art. 20 TRLIS.

\footnotetext{
${ }^{19}$ Cordón Ezquerro, Teodoro y Gutiérrez Luosa, Manuel, “La subcapitalización: Tratamiento jurídicotributario y su compatibilidad con el principio de no discriminación." En Cordón Ezquerro, Teodoro (Dir.) Manual de Fiscalidad Internacional, Tercera Edición, Instituto de Estudios Fiscales, Madrid, 2007, p.979-1019. p. 991.
} 
Ahora bien, otro supuesto es el de un EP sito en España recibe financiación de entidades residentes en España o por otros EP radicados en España. La Dirección General de Tributo ha entendido que los préstamos entre una entidad vinculada residente y la sucursal española de una entidad financiera no residente, no cumple con el elemento subjetivo de la subcapitalización previsto por el artículo 20 TRLIS, puesto que si se atiende a la finalidad de la norma, no existe la posibilidad de traslado de la base imponible a otro Estado ${ }^{20}$. Así las cosas, se ha entendido que a pesar de que el EP es un no residente, el art. 20 TRLIS no es aplicable pues no hay riesgo de traslación de la base imponible por fuera del Estado Español. Esta es pues una finalidad que la jurisprudencia ha inducido del artículo 20 TRLIS, que en todo caso, se queda corta para cerrar el paso a la elusión fiscal pero cuyo fundamento normativo no permite variar.

Una excepción prevista en el art. 20 TRLIS a que se trate de entidades vinculadas y a que la prestamista sea un no residente, es la financiación indirecta. Se trata de un concepto indeterminado. Por esta vía se busca atajar aquellas operaciones back to back loan, y aquellos supuestos de intermediación en el préstamo. Se detecta que el problema en todos estos casos es probar la relación entre el prestamista aparente y el prestamista real. Operaciones complejas como la titularización de los créditos, no parecen ser alcanzadas por el concepto de endeudamiento indirecto ya que la titulización se da sobre un conjunto de préstamos y en un momento posterior a la concesión del crédito. Ahora bien, en la práctica la mayor discusión se ha dado en torno a si las garantías constituyen o no endeudamiento indirecto ${ }^{21}$. Según la más reciente jurisprudencia, es necesario que se pruebe como se afectan las bases imponibles españolas por medio de un traslado de estas entidades no residentes

\footnotetext{
${ }^{20}$ Consulta general 2476-03, de 26 de diciembre de 2003, de la Subdirección General de Impuestos sobre las Personas Jurídicas. LA LEY 2738/2003.

${ }^{21}$ Entre otros: Dirección General del Tributo, SG de Impuestos sobre las Personas Jurídicas, Consulta Vinculante No. 0503 de 30 de marzo de 1998. Disponible en: http://petete.minhac.es/Scripts/know3.exe/tributos/consulta/texto.htm?Consulta=.EN+Normativa+(Ley

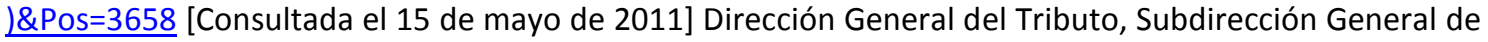
Impuestos sobre la Renta de las Personas Jurídicas, Consulta General, No. 1210 de 20 de junio de 2001, LA LEY 1361/2001. Audiencia Nacional, Sala de lo Contencioso-Administrativo, Sección 7ạ, Sentencia de 9 Oct. 2006, rec. 109/2006, LA LEY 124963/2006. Audiencia Nacional, Sala de lo ContenciosoAdministrativo, Sección 7ạ, Sentencia de 23 Abr. 2007, № de Recurso: 295/2006, LA LEY 12703/2007. Sanz Gadea, Eduardo, Medidas Anti-elusión Fiscal, Documento IEF 08/09, Instituto de Estudios Fiscales, Madrid, 2009. Disponible

en: http://www.ief.es/documentos/recursos/publicaciones/documentos trabajo/2009 08.pdf p. $27-31$. [Consultada el 15 de mayo de 2011], p. 35. Palao Taboada, Carlos, "La Subcapitalización", En Serrano Antón, Fernando (Dir.), Fiscalidad Internacional, Cuarta edición, CEF, Madrid, 2010, p. 999-1036. p. 1006. Cordón Cordón Esquero, Teodoro y Gutiérrez Luosa, Manuel, "La subcapitalización: Tratamiento jurídico-tributario y su compatibilidad con el principio de no discriminación." En Cordón Ezquerro, Teodoro (Dir.) Manual de Fiscalidad Internacional, Tercera Edición, Instituto de Estudios Fiscales, Madrid, 2007, p.979-1019, p. 993. Palao Taboada, Carlos, "La subcapitalización y los Convenios de Doble Imposición”, en: Revista de Contabilidad y Tributación, número 137-138, Madrid, 1994. p. 286. Falcón y Tella, Ramon, “Art. 20 subcapitalización”, en: AA.VV. Comentarios a la Ley del Impuesto sobre Sociedades, Marcial Pons, Madrid, 2000. p. 286. García-Herrera Blanco, Cristina, Precios de Transferencia y otras Operaciones Vinculadas en el Impuesto sobre Sociedades, Instituto de Estudios Fiscales, Madrid, 2001, p. 233.
} 
vinculadas, pues supuestamente ese es el fin de la norma ${ }^{22}$. Esta conclusión que podría parecer desproporcionada, aunque lo cierto es que el texto de la norma no permite visualizar una finalidad distinta. Por ejemplo, podría pensarse que hay endeudamiento indirecto cuando la entidad financiera intermediaria no hubiere concedido el préstamo sin la intervención de una garantía solidaria o real prestada por una entidad financiera no residente, en el entendido de que la finalidad del art. 20 TRLIS es corregir, a efectos del Impuesto de Sociedades, el Impuesto de Renta de Personas Físicas y el Impuesto de Renta de no Residentes, las fallas del mercado existente en las decisiones de financiación. Esta posibilidad interpretativa existe, pero ciertamente es discutible dada la redacción de la norma.

El apartado 4 del art. 20 TRLIS excluye del ámbito subjetivo de la normativa antisubcapitalización a las entidades vinculadas residentes en otro Estado miembro de la Unión Europea, a menos de que se trate de un paraíso fiscal. Esta excepción se introdujo como respuesta a la citada sentencia Lankhorst-Hoborst ${ }^{23}$ que encontró la norma anti-subcapitalización alemana contraria a la libertad de establecimiento consagrada en el Tratado Fundacional de la Unión Europea (TFUE) ${ }^{24}$. La solución española ha dejado en entredicho el fundamento del principio de independencia ${ }^{25}$. Además, no era la única alternativa que se tenía, pues se pudo haber ampliado de forma que no se hiciera referencia alguna a la condición de residente como sugirió LUCAS DURÁN ${ }^{26}$, lo que implicaba ampliar la finalidad de la norma a los casos de

\footnotetext{
${ }^{22}$ Tribunal Supremo, Sala Tercera, de lo Contencioso-Administrativo, Sección 2ạ, Sentencia de 17 Mar. 2011, rec. 5871/2006, LA LEY 14311/2011.

${ }^{23}$ Tribunal de Justicia de la Unión Europea, Sala Quinta, Sentencia de 12 Dic. 2002, proc. C-324/2000, asunto Lankhorst-Hoborst. LA LEY 209152/2002

${ }^{24}$ Helminem, Marjaana, The International Tax Law Concept of Dividend, Wolters Kluwer International BV, Alphen aan den Rijn (The Netherlands), 2010. p. 210-211. En palabras de Lucas Durán "el Tribunal de Justicia recoge en primer lugar que las situaciones traídas a colación en el procedimiento son efectivamente comparables como requisito previo a la existencia de discriminación. En efecto, el Estado alemán había alegado que no se trata de una disposición discriminatoria por cuanto que los no residentes no son los únicos que están sometidos a dicha regla jurídica de recalificación obligatoria de intereses en dividendos encubiertos, pues también es aplicable a algunos residentes como las personas jurídicas de Derecho público y a las que ejerzan una actividad económica en determinados sectores específicos o que desempeñen funciones de interés general. Frente a esta alegación del Estado alemán, el TJCE sigue la tesis mantenida por el Abogado General en sus conclusiones y declara que la comparación no debía realizarse entre entidades no residentes y las residentes de Derecho público o de determinados sectores económicos -especialmente privilegiados por el ordenamiento alemán-, sino entre dos entidades de Derecho privado y con fines lucrativos que por el mero hecho de no ostentar residencia alemana se encontrarán necesariamente sujetas a un régimen de tributación al que no se encuentran compelidas las entidades residentes de las mismas características." Lucas Durán, Manuel "STJCE 12-12-2002, Lankhorst-Hohorst versus Finanzamt Steinfurt, As. C-324/00. Libertad de establecimiento; normas tributarias sobre subcapitalización; distribución encubierta de beneficios; coherencia del régimen fiscal; evasión fiscal." en: Crónica Tributaria, No. 117, Madrid, 2005, p. 3-9.

${ }^{25}$ Palao Taboada, Carlos, "La Subcapitalización", En Serrano Antón, Fernando (Dir.), Fiscalidad Internacional, Cuarta edición, CEF, Madrid, 2010, p. 999-1036, p. 1021.

${ }^{26}$ Lucas Durán, Manuel “STJCE 12-12-2002, Lankhorst-Hohorst versus Finanzamt Steinfurt, As. C-324/00. Libertad de establecimiento; normas tributarias sobre subcapitalización; distribución encubierta de beneficios; coherencia del régimen fiscal; evasión fiscal." en: Crónica Tributaria, No. 117, Madrid, 2005. p. $3-9$, p. 9
} 
subcapitalización entre residentes, situación que también envuelve efectos negativos para la recaudación y que pudo haberse corregido.

Es importante referir que el caso Lankhorst-Hoborst ha sido tenido en cuenta por el Tribunal Supremo Español ${ }^{27}$ y la Audiencia Nacional ${ }^{28}$ para inaplicar la norma de subcapitalización española anterior a la vigente, la cual no excluía a los residentes en la Unión Europea, por considerarla contraria a la libertad de establecimiento en los mismos términos de la sentencia.

No obstante, la jurisprudencia más reciente del Tribunal de Justicia de la Unión Europea, como es el caso Test Claimants in the Thin Cap Group Litigation ${ }^{29}$, parece permitir la distinción entre residentes y no residentes, siempre que la normativa de

27 Tribunal Supremo, Sala Tercera, de lo Contencioso-Administrativo, Sección 2ạ , Sentencia de 21 Feb. 2008, rec. 8310/2002. LA LEY 8984/2008. Tribunal Supremo, Sala Tercera, de lo ContenciosoAdministrativo, Sección 2aa, Sentencia de 6 Abr. 2011, rec. 103/2007. LA LEY 14493/2011. Tribunal Supremo, Sala Tercera, de lo Contencioso-Administrativo, Sección 2aㅡ, Sentencia de 17 Mar. 2011, rec. 5871/2006. LA LEY 14311/2011.

${ }^{28}$ La Audiencia Nacional Española ha indicado "El abandono de la discusión desde esa perspectiva no se justifica por la existencia de contradicciones, que, en su caso, habría que solventar, sino porque su análisis resulta innecesario, pues parece incontestable que, a partir de la sentencia del Tribunal de Justicia de las Comunidades Europeas de 12 de diciembre de 2002 , Lankhorst-Hohorst (asunto C324/00), publicada en el Boletín Oficial de las Comunidades Europeas de 8 de febrero de 2003 (serie C, no 31, pág. 2), el tratamiento diferente dispensado en el impuesto sobre sociedades a dos compañías nacionales que obtienen financiación de otra con la que se encuentran vinculada, en función de que esta segunda resida en el propio país o lo haga en otro Estado miembro, de modo que, en el segundo caso, los intereses pagados queden sometidos a un régimen tributario más desfavorable, contradice la libertad de establecimiento e infringe el art. 43 del Tratado constitutivo de la Comunidad Europea". Además, que el trato que daba el artículo 16.9 LIS "sólo se dispensa a las empresas españolas que reciben préstamos de sus matrices establecidas en otros Estados miembros, mientras que las que realizan las mismas operaciones con entidades residentes en nuestro país disfrutan de un régimen fiscal más favorable, se obstaculiza la libertad de establecimiento proclamada en el art. 43 del Tratado constitutivo de la Comunidad Europea. Este precepto, dada su primacía y su efecto directo [véase, por todas, la sentencia de 11 de diciembre de 2007 The International Transport Workers' Federation et The Finnish Seamen's (C-438/05), apartado 68], desplaza al art. 16, apartado 9, de la Ley 61/1978 [sentencia de 9 de marzo de 1978, Simmenthal (asunto 106/77)], provocando, por oponerse a sus dictados, la nulidad de la liquidación tributaria recurrida, así como la de las resoluciones económico-administrativas que lo confirmaron." Audiencia Nacional, Sala de lo Contencioso-Administrativo, Sección 2a ${ }^{-}$, Sentencia de 5 Nov. 2009, rec. 169/2006. LA LEY 210244/2009.

29 "El art. 43 CE se opone a una legislación de un Estado miembro que restringe la facultad de una sociedad residente de deducir a efectos fiscales los intereses de un préstamo financiero concedido por una sociedad matriz, directa o indirecta, residente en otro Estado miembro o por una sociedad residente en otro Estado miembro controlada por tal sociedad matriz, sin sujetar a dicha restricción a una sociedad residente que haya obtenido el préstamo de una sociedad también residente, excepto si, por un lado, dicha legislación se basa en un examen de elementos objetivos y verificables que permiten identificar la existencia de un montaje puramente artificial con fines exclusivamente fiscales al establecer la posibilidad de que el contribuyente pueda presentar, en su caso, y sin estar sujeto a restricciones administrativas excesivas, elementos relativos a los motivos comerciales subyacentes a la transacción de que se trata y, por otro lado, si, demostrada la existencia de tal montaje, la referida legislación sólo califica dichos intereses como beneficios distribuidos en la medida en que superen lo que se habría acordado en condiciones de libre competencia", Unión Europea, Tribunal de Justicia de la Unión Europea, Sala Gran Sala, Sentencia de 13 Mar. 2007, proc. C-524/2004, asunto Test Claimants in the Thin Cap Group Litigation. LA LEY 8926/2007. 
subcapitalización se base en un examen de elementos objetivos y verificables que indiquen la existencia de un montaje artificial con efectos exclusivamente fiscales y que permitan al contribuyente presentar prueba de los motivos económicos subyacentes. Sin embargo, esta jurisprudencia no ha tenido acogida ni por el legislador ni por la jurisprudencia española.

La doctrina ha sugerido que posiblemente el art. 20 TRLIS resulte contrario a la libertad de movimiento de capitales, ya que podría entenderse que las normas antisubcapitalización producen "un efecto disuasorio tanto para la entidad vinculada no residente prestamista potencial como para la prestataria residente ${ }^{\prime 30}$. Ello haría que la cláusula anti-subcapitalización no fuese aplicable en operaciones donde la financiación procede de un residente en terceros países, ya que como es sabido, la libertad de movimiento de capitales se propugna tanto de los Estados miembros cómo de terceros países. La sentencia del caso Test Claimants in the Thin Cap Group Litigation, en los apartados 33 y 34, se abstuvo de analizar si las normas anti-subcapitalización son contrarias la libertad de movimiento de capitales o no, bajo lo que LUCAS DURÁN ha denominado la teoría de la accesoriedad de las libertades según la cual, en los "supuestos en que la libertad de movimiento de capitales sea accesoria a otra libertad se aplicarán las disposiciones de esta y no de aquella..." ${ }^{31}$. En todo caso, debe resaltarse que existe un grado de incertidumbre sobre inaplicación del art. 20 TRLIS por ser contrario a la libertad de circulación de capitales. Además, si así fuere, se reduciría ostensiblemente el alcance de esta medida antielusión.

Finalmente, otro supuesto de restricción del ámbito subjetivo de la norma antisubcapitalización ocurre cuando resulta aplicable un CDI, la jurisprudencia del TS en España ha entendido que el art. 20 TRLIS se desactiva (derogación tácita o aplicación prevalente por el principio de especialidad) por resultar contrario al principio de no discriminación previsto en el art. $24 \mathrm{MCOCDE}^{32}$. Ello, salvo que el mismo CDI exceptúe la norma de no discriminación a la aplicación de las reglas internas de subcapitalización como ocurre en varios $\mathrm{CDI}$ españoles.

\section{2. ÁMBITO OBJETIVO DE APLICACIÓN}

Ahora bien, el ámbito objetivo de la cláusula española anti-subcapitalización parte de la base de una ratio fija de 1 del capital fiscal por 3 de endeudamiento, como

\footnotetext{
30 Palao Taboada, Carlos, “La Subcapitalización”, En Serrano Antón, Fernando (Dir.), Fiscalidad Internacional, Cuarta edición, CEF, Madrid, 2010, p. 999-1036, p. 1028

${ }^{31}$ Lucas Durán, Manuel, “Fiscalidad y Libre Circulación de Capitales y Pagos en el Derecho Comunitario Europeo", en: Labeaga Azcona, Jose Maria y Chico de la Cámara, Pablo (Dirs.), Repercusiones Tributarias de la Unión Europea, Instituto de Estudios Fiscales - Universidad Rey Juan Carlos, Madrid, 2010, p.85127, p. 101.

${ }^{32}$ Tribunal Supremo, Sala Tercera, de lo Contencioso-Administrativo, Sección 2ạ, Sentencia de 6 Abr. 2011, rec. 103/2007. LA LEY 14493/2011. Tribunal Supremo, Sala Tercera, de lo ContenciosoAdministrativo, Sección 2a a Sentencia de 1 Oct. 2009, rec. 1596/2004. LA LEY 237382/2009. Tribunal Supremo, Sala Tercera, de lo Contencioso-Administrativo, Sección 2aㅡ, Sentencia de 17 Mar. 2011, rec. 5871/2006. LA LEY 14311/2011. Tribunal Supremo, Sala Tercera, de lo Contencioso-Administrativo, Sección 2a ${ }^{a}$, S de 11 Feb. 2000, rec. 25/1999. LA LEY 35806/2000. Tribunal Supremo, Sala Tercera, de lo Contencioso-Administrativo, Sección 2ª , Sentencia de 21 Feb. 2008, rec. 8310/2002. LA LEY 8984/2008
} 
límite, calculados como media a lo largo del periodo. El cálculo se hace por cada relación entre los deudores y acreedores vinculados directa o indirectamente, salvo que se compruebe que en financiaciones circulares, esto es cuando distintas filiales sirven de intermediaria de la matriz para financiar a la entidad residente en España, caso en el cual se sumará el endeudamiento directo e indirecto prestado por la matriz. Debe ser endeudamiento neto, compensándose así las deudas correlativas. El endeudamiento debe ser remunerado, requisito que se cumple con las remuneraciones ficticias (art. 16.1 TRLIS) y presuntas (art. 5 TRLIS). Por su parte el capital fiscal se asimila a los fondos propios.

La distinción entre endeudamiento y capital fiscal se hará teniendo en cuenta la clasificación que se encuentre en el Plan General de Contabilidad (PGC) y la finalidad del art. 20 TRLIS, cual es la de impedir la deducibilidad de intereses que envuelvan una financiación con características de financiación interna. SANZ GADEA, por su parte, aboga por una calificación de acuerdo con las normas contables ${ }^{33}$.Descartamos el uso de criterios de calificación contables (art. 34.2 Código de Comercio), por existir normas especiales de calificación en materia tributaria que se adecuan más a la construcción dogmática de esta rama del Derecho y a los principios constitucionales que sobre la misma se despliegan, en especial el de reserva de ley y seguridad jurídica. ${ }^{34}$

El art. 20 TRLIS permite de manera ex ante acordar con la Administración una ratio superior a la prevista, siempre que se respete el principio de independencia y no se trate de operaciones con paraísos fiscales. Esta excepción ha generado polémica en la doctrina que ha vacilado entre considerar la ratio como una presunción ${ }^{35}$, una ficción $^{36}$, o una mezcla de ambas ${ }^{37}$, y con ello, se ha indagado sobre la naturaleza de estos acuerdos con la Administración. La posición más clara, a nuestro juicio es la que plantea que esta excepción se hace al presupuesto de hecho de una verdadera ficción existente en el art. 20 TRLIS que opera cómo un presupuesto de hecho subrogatorio ${ }^{38}$.

La ratio también encuentra límites que se deducen de la especial interacción de los CDI con el ordenamiento interno, ya que, en aplicación de un CDI, no se dará el presupuesto objetivo de la norma de subcapitalización si no se comprueba además de la superación de la ratio, que la operación no responde al principio de independencia

\footnotetext{
33 Sanz Gadea, Eduardo, Medidas Anti-elusión Fiscal, Documento IEF 08/09, Instituto de Estudios Fiscales, $\quad$ Madrid, $2009 . \quad$ Disponible en: http://www.ief.es/documentos/recursos/publicaciones/documentos trabajo/2009 08.pdf p. 27-31. [Consultada el 15 de mayo de 2011], p. 27.

34 Ferreiro Lapatza, José J., “Complicación y Simplificación. Contabilidad y Fiscalidad”, en: Revista Quincena Fiscal, núm. 15-16, 2006, p. 15-24. p. 15.

35 De Arrespacochaga, Joaquín, Planificación Fiscal Internacional, segunda edición, Marcial Pons, Madrid, 1998. p. 96.

${ }^{36}$ Calvo Vérguez, Juan, “5.6. La subcapitalización”, en: AA.VV. Fiscalidad Práctica. Tomo III: Impuesto de Sociedades. Thomson Reuters, Cizur Menor, 2010. p. 496

${ }^{37}$ Eseverri Martínez, Ernesto, Presunciones legales y Derecho Tributario. Marcial Pons, Madrid, 1995, p. 97-95

38 García-Herrera Blanco, Cristina, Precios de Transferencia y otras Operaciones Vinculadas en el Impuesto sobre Sociedades, Instituto de Estudios Fiscales, Madrid, 2001. p. 227-231.
} 
del art. $9 \mathrm{MCOCDE}^{39}$. Posiciones contrarias se encuentran en la doctrina y jurisprudencia española pero llevan a desconocer las reglas de interpretación del efecto útil, ya que supondrían la completa inaplicación del art. 20 TRLIS.

Los efectos del art. 20 TRLIS se resumen una recalificación de los intereses que correspondan al exceso en dividendos. Ello conlleva a que para el residente los pagos por la financiación no serán gastos deducibles, debiendo hacerse un ajuste positivo a la base imponible del IS. Para el no residente, la retención en la fuente en situaciones de CDI puede diferir. Pero por fuera de esas situaciones y en los casos comunitarios, el tipo de la retención es idéntico. Siendo el deber de retener del prestatario residente, éste será quien resulte obligado, en la práctica, a pagar las diferencias en el tipo de retención. En todo caso, los conflictos de calificación de CDI podrán surgir si el Estado de residencia del prestatario no acepta la recalificación y por tanto deniega las medidas para evitar la doble imposición económica.

\section{TERCERA PARTE: ANÁLISIS DE LA COMPATIBILIDAD DEL ART. 20 TRLIS CON LOS CDI: UNA PROPUESTA DE LEGE DATA}

Los CDI son normas internacionales que deben integrarse como una plantilla con el orden interno de forma de que, de ser posible, no resulte contradictorio, pero en caso tal, las normas convencionales prevalecerán sobre las internas por tener una competencia especial sobre el ámbito de la realidad que regulan (ámbito de aplicación objetivo, subjetivo, material, temporal) ${ }^{40}$. Existen tres asuntos que son de especial controversia entre el art. 20 TRLIS y los CDI que es su respeto al MCOCDE en los art. 9, a los arts. 10 y 11 , y el 24.

Para la jurisprudencia del TS español, el art. 20 TRLIS es contrario al principio de no discriminación previsto en el art. $24 \mathrm{MCOCDE}$, no obstante consideramos que existe una interpretación alternativa igualmente válida y que expondremos a continuación.

El art. 9 MCOCDE permite a los ordenamientos internos corregir la base imponible de empresas vinculadas residentes en cada uno de los estados contratantes siempre que dichas correcciones se adecuen al principio de independencia. Se discute si se aplica a las correcciones derivadas de las normas anti-subcapitalización, a nuestro juicio las condiciones aceptadas o impuestas a que se refiere dicho artículo comprende aquellas que pueden exigirse para configurar un instrumento financiero como

\footnotetext{
${ }^{39}$ En sentido similar el Tribunal Superior de Justicia de Madrid, Sala de lo Contencioso-Administrativo, Sección 5ạ, Sentencia de 28 Mar. 2008, rec. 590/2004. LA LEY 41328/2008. No compartimos los argumentos de la sentencia en cuanto a que es una presunción, pero si estamos de acuerdo con sus conclusiones que son la Administración debe probar que la operación no responde al principio de independencia. Así las cosas, el presupuesto de la ficción del art. 20 TRLIS en situaciones de CDI se ve adicionado por un requisito que es que la operación se adecua al principio de independencia previsto en el art. 9 MCOCDE.

40 Lang, Michael, Introduction to the Law of Double Taxation Conventions, IBFD-LINDE, Amsterdam, 2010, p. 44. VOGEL figurativamente indica que los CDI funcionan como una "plantilla" que se sitúa sobre el Derecho interno y cubre ciertas partes. Vogel, Klaus, On Double Taxations Conventions, Third edition, Kluwer Law International, Denveter, 1999. p.31-32. núm. 56.
} 
endeudamiento o capital, con lo cual si incluye a las normas anti-subcapitalización. Así las cosas, el art. 20 TRLIS es permitido por el CDI a condición de que aplique una limitación consistente en que no habrá ficción de subcapitalización con sus consecuentes efectos hasta que además del incumplimiento de la ratio, se verifique que la operación se encuentra en condiciones contrarias al principio de independencia. Las operaciones por debajo de la ratio operarán como un puerto seguro (safe harbour).

Las definiciones de dividendos e intereses previstas en los CDI pueden verse afectadas por el efecto de reclasificar los intereses en dividendos que prevé el art. 20 TRLIS y pueden dar lugar a conflictos de calificación. El punto de partida de la solución es indudablemente el que las clasificaciones incorporadas a efectos de los CDI tienen un significado autónomo y prevalecen sobre las internas. El problema esencialmente lo presenta la remisión que incorpora el art. 10.3 MCOCDE a "las otras participaciones sociales sujetas al mismo régimen fiscal de las acciones por el Estado de residencia de la sociedad que hace la distribución". Son pertinentes las siguientes aclaraciones:

1. Antes de la remisión al orden interno, aparece el concepto autónomo de participaciones sociales, el cual opera como un límite consistente en verificar si existe una asunción de riesgos empresariales con la financiación. Mientras exista tal asunción de riesgos podrá recalificarse la financiación en dividendos, y mientras no exista la misma, serán intereses. Se exige además, que la recalificación evidencie que la operación no respeta el principio de independencia para que pueda respetar las definiciones autónomas de los CDI, en concreto el articulo 11.6. MCOCDE. En estos casos, entendemos que el Estado de la residencia estaría obligado a la luz del CDI a aceptar la recalificación dada por el Estado de la fuente, en atención a su norma interna de subcapitalización.

2. La OCDE sugiere que los Estados son libres de aceptar esas recalificaciones fuera de estas condiciones, pero que el Estado de la Residencia también debería estar vinculados cuando contenga en su normativa preceptos antisucapitalización similares a los que utiliza el Estado de la fuente.

3. En los casos en que los CDI, en su redacción no requieran que los dividendos provengan de "participaciones sociales", debe entenderse que la remisión al orden interno del Estado de la fuente de los dividendos es más amplia y el requisito de la asunción de riesgos no es aplicable, estando obligado el Estado de la Residencia a aceptar la recalificación por cuenta de una norma anti-subcapitalización ${ }^{41}$.

4. Las diferencias en la interpretación del criterio de asunción de riesgos, del alcance de la remisión a la ley interna o de la propia aplicación de la norma de subcapitalización entre los Estados contratantes podrá causar doble imposición. A tal

\footnotetext{
${ }^{41}$ Helminem, Marjaana, The International Tax Law Concept of Dividend, Wolters Kluwer International BV, Alphen aan den Rijn (The Netherlands), 2010, p. 220-221.
} 
efecto, el procedimiento amistoso, el arbitraje previsto en los CDI y el comunitario serán los instrumentos llamados a solucionar estas cuestiones problemáticas ${ }^{42}$.

Ahora bien, el art. 24 MCOCDE prohíbe la discriminación de los EP, de las empresas controladas por residentes del otro Estado contratante y los tratos discriminatorios en la deducibilidad por pagos hechos por una empresa de un Estado contratante a otra empresa de otro Estado contratante. La tendencia en la doctrina y la jurisprudencia española e internacional parece ser la de considerar de plano, que las normas anti-subcapitalización que parten de una distinción entre residentes y no residentes son contrarias al art. 24.4 y $24.5 \mathrm{MCOCDE}^{43}$. Nos sumamos a la posición de la OCDE en el Modelo de Convenio del año 2010 (comentarios 78 y 79 al art. 24) y consideramos que la diferenciación está permitida, pues de un lado, el primer artículo expresamente se exceptúa frente al art. 9 y 11.6 MCOCDE que, según hemos dicho, da cabida a las normas internas anti-subcapitalización. El art. 24.5 por su parte, se limita a las discriminaciones por razón de su participación por empresas del otro Estado contratante, lo cual no ocurre cuando la diferenciación es generalizada a todos los no residentes. Además, se infiere de la finalidad del CDI la prevención de la elusión fiscal, de forma que en casos donde exista verdaderamente artificialidad y abuso, el CDI no aplicará, ello incluye las cláusulas al art. 24 MCOCDE, de tal forma las cláusulas antisubcapitalización no están prohibidas per se, si se limitan a atacar los casos meramente artificiales. Por artificialidad habrá de entenderse lo que no está acorde con el principio de arm's lenght.

Debe mencionarse que algunos CDI salvaguardan las clausulas de subcapitalización internas expresamente. Un primer grupo de CDI lo hace compatibilizándolas con todas las cláusulas convencionales (ejemplo. CDI EspañaMéxico). Un segundo grupo se restringe a la no discriminación dejando aplicables las restricciones que derivan del art. 9 MCOCDE (Por ejemplo, los CDI de España con Francia, Suráfrica, Islandia, Israel, Costa Rica, República Helénica).

Se plantea la pregunta acerca de la interpretación dinámica y estática de estas salvaguardas. La forma en que han sido reguladas estas normas en los CDI suscritos por España, da a entender que la interpretación debe ser dinámica ${ }^{44}$. En todo caso, existe el límite para los Estados de obrar de buena fe de acuerdo con lo previsto en la CVDT, so pena de incurrir en treaty dodging ${ }^{45}$. Finalmente, debe aclararse que tales

${ }^{42}$ Comentarios 67 y 68 al art. $23 \mathrm{~A}$ y $23 \mathrm{~B}$ del MCOCDE.

${ }^{43}$ García Prats, Francisco Alfredo, La Cláusula de no Dictriminación en los Convenios para Evitar la Doble Imposición Internacional", En Serrano Antón, Fernando, Fiscalidad Internacional, 4o edición, CEF, Madrid, 2010. p. 1121-1154, p. 1149-1154. Martín Jiménez, Adolfo, “No discriminación”, Carmona Fernández, Néstor (Coord.) en, Convenios Fiscales Internacionales y Fiscalidad de la Unión Europea", CISS, Valencia, 2010, pp. 591-619.

${ }^{44}$ Rocha, Sergio André, Interpretation of Double Taxation Conventions. General Theory and Brazilian Perspective, Kluwer Law International BV, The Hague, 2009, p. 122 y ss.

${ }^{45}$ Aguas Alcalde, Emilio, Tributación Internacional de los Rendimientos de Trabajo, Aranzadi, Cizur Menor, 2003. p. 62. Villanueva Gutiérrez, Walker, "Conflictos de Calificación en los Convenios para Evitar la Doble Imposición”, En García Novoa, Cesar y Hoyos Jiménez, Catalina (Coords). El tributo y su aplicación. Perspectivas para el siglo XXI, Tomo II, Marcial Pons, Buenos Aires, 2008, p. 1281-1301, p. 1293. 
salvaguardias se refieren a las medidas específicas anti-subcapitalización y excluyen otro tipo de cláusulas antielusión.

\section{CONCLUSIONES}

1. En cuanto al ámbito subjetivo, visto el panorama de aplicación del art. 20 TRLIS, es evidente que hay que hacer esfuerzos interpretativos para logar sostener su aplicación a las situaciones cobijadas por un CDI. En todo caso, este esfuerzo choca con la jurisprudencia entiende el art. 20 TRLIS como contrario a los CDI. Lo mismo ocurre con los EP donde existen graves dudas interpretativas en cuanto a si están cubiertos o no por la normativa. En el ámbito comunitario, legalmente, el articulo desde aparece desactivado para las operaciones con residentes en la UE y según doctrina, podría no ser aplicable a residentes de terceros países en situaciones que resulten contrarias a la libertad de establecimiento. Tampoco resulta de aplicación a las entidades financieras. Todo lo anterior hace que el art. 20 TRLIS tenga un grado mínimo de aplicación y su derogatoria podría pasar desapercibida en la práctica, pues en buena medida ya se entiende que lo está para la gran mayoría de los casos.

2. Hemos dejado claro que tanto en el ámbito del Derecho Comunitario Europeo como en el de los CDI, las normas de subcapitalización están sometidas al principio de independencia. De esta forma, las normas que contemplan una ratio fija -como el art. 20 TRLIS- deben inaplicarse cuando se trate de operaciones acordes con el principio de independencia. Ello causa cuestionamientos sobre la utilidad de tales clausulas; sobre todo, porque cuando esa ratio fija es una ficción, como ocurre con en el art. 20 TRLIS, la norma se convierte en un peligroso puerto seguro que encubrirá situaciones meramente artificiales, siendo muy discutible que sea posible atacarlas por medio de otras normas antielusión.

3. Por todo lo anterior, resulta conveniente una reforma del art. 20 TRLIS en el sentido de que se aplique sin distinción a los no residentes, lo cual puede permitir atacar situaciones internas de subcapitalización que también resultan elusivas. El ámbito objetivo debería responder a unos sistemas de presunciones que no limiten a la Administración a probar una ratio inferior ni a los particulares a probar una ratio mayor, todo sobre la base del principio de independencia. En cuanto a los efectos, parece ser suficiente con que se deniegue la deducibilidad únicamente, sin que haya lugar a la recalificación en dividendos, para así obviar complicaciones con las definiciones propias de los CDI. 


\section{Bibliografía}

Aguas Alcalde, Emilio, Tributación Internacional de los Rendimientos de Trabajo, Aranzadi, Cizur Menor, 2003.

Báez Moreno, Andrés, Normas Contables e Impuesto sobre Sociedades, Aranzadi, Cizur Menor, 2005.

Calvo Vérguez, Juan, "5.6. La subcapitalización”, en: AA.VV. Fiscalidad Práctica. Tomo III: Impuesto de Sociedades, Thomson Reuters, Cizur Menor, 2010.

Cordón Esquero, Teodoro y Gutiérrez Luosa, Manuel, "La subcapitalización: Tratamiento jurídico-tributario y su compatibilidad con el principio de no discriminación." En Cordón Ezquerro, Teodoro (Dir.) Manual de Fiscalidad Internacional, Tercera Edición, Instituto de Estudios Fiscales, Madrid, 2007, p.979-1019.

De Arrespacochaga, Joaquín, Planificación Fiscal Internacional, segunda edición, Marcial Pons, Madrid, 1998.

Eseverri Martínez, Ernesto, Presunciones legales y Derecho Tributario. Marcial Pons, Madrid, 1995.

Falcón y Tella, Ramon, "Art. 20 subcapitalización”, en AA.VV. Comentarios a la Ley del Impuesto sobre Sociedades, Marcial Pons, Madrid, 2000.

Ferreiro Lapatza, José J., "Complicación y Simplificación. Contabilidad y Fiscalidad”, en: Revista Quincena Fiscal, núm. 15-16, 2006. p. 15-24.

García Prats, Francisco Alfredo, La Cláusula de no Dictriminación en los Convenios para Evitar la Doble Imposición Internacional", En Serrano Antón, Fernando, Fiscalidad Internacional, 4ํe edición, CEF, Madrid, 2010. p. 1121-1154.

García-Herrera Blanco, Cristina, Precios de Transferencia y otras Operaciones Vinculadas en el Impuesto sobre Sociedades, Instituto de Estudios Fiscales, Madrid, 2001.

Helminem, Marjaana, The International Tax Law Concept of Dividend, Wolters Kluwer International BV, Alphen aan den Rijn (The Netherlands), 2010.

Lang, Michael, Introduction to the Law of Double Taxation Conventions, IBFD-LINDE, Amsterdam, 2010.

Lucas Durán, Manuel "STJCE 12-12-2002, Lankhorst-Hohorst versus Finanzamt Steinfurt, As. C-324/00. Libertad de establecimiento; normas tributarias sobre subcapitalización; distribución encubierta de beneficios; coherencia del régimen fiscal; evasión fiscal." en: Crónica Tributaria, No. 117, Madrid, 2005. p. 3-9.

"Fiscalidad y Libre Circulación de Capitales y Pagos en el Derecho Comunitario Europeo", en: Labeaga Azcona, Jose Maria y Chico De La Cámara, Pablo (Dirs.), 
Repercusiones Tributarias de la Unión Europea, Instituto de Estudios Fiscales Universidad Rey Juan Carlos, Madrid, 2010. p. 85-127.

Martín Jiménez, Adolfo, "No discriminación”, En Carmona Fernández, Néstor (Coord.) en: Convenios Fiscales Internacionales y Fiscalidad de la Unión Europea", CISS, Valencia, 2010, p. 591-619.

Makhmudova, Kamila. "Conflicts of Qualification and Thin Capitalization Rules", en: Burgstaller, Eva y Haslinger, Katharina (Eds.), Conflicts of Qualification in Tax Treaty Law, LINDE, Viena, 2007, p. 251-267.

OCDE, Modelo de convenio tributario sobre la Renta y sobre el Patrimonio versión abreviada 22 julio 2010, Instituto de Estudios Fiscales, Madrid, 2011.

OECD, Harmful Tax Competition. An Emergiong Global Issue, París, 1998.

OECD, Committee of Fiscal Affairs, Issues in International Taxation No. 2 -Thin Capitalization and Taxation of Entertainers, Artistes and Sportmen, París, 1987.

OECD, Transfer Pricing Guidelines for Tax Administrations and Multinational Enterprises, París, 1995.

OECD, Transfer Pricing Guidelines for Multinational Enterprises and Tax Administrations, París, 2010.

OECD, Transfer Pricing and Multinational Enterprises, París, 1979. (OCDE, Informe: Los precios de Transferencia y las empresas Multinacionales, París, 1979.)

OECD - Centre for Tax Policy And Administration (TPA), Proposals for improving mechanisms for the resolution of tax treaty disputes. Public discussion draft, Paris, February, 2006.

OECD, Model Tax Convention on Income and on Capital: Condensed Versión 2010, OECD publishing, DOI. Disponible en: http://www.oecdilibrary.org/taxation/model-tax-convention-on-income-and-on-capitalcondensed-version-2010 mtc cond-2010-en [consultada el 15 de marzo de 2011].

ONU, Manual of the Negotiation of Bilateral Tax Treaties between Developed and Developing Countries, United Nations, New York, 2003.

ONU, Contributions to International Co-operation in Tax Matters, United Nations Department of International and Social Affairs, United Nations Publications, 1988.

Palao Taboada, Carlos, "La Subcapitalización", En Serrano Antón, Fernando (Dir.), Fiscalidad Internacional, Cuarta edición, CEF, Madrid, 2010, p. 999-1036.

“La subcapitalización y los Convenios de Doble Imposición", Revista de Contabilidad y Tributación, número 137-138, 1994.

Palombo, Maria Eugenia, "Italy", International Transfer Pricing Journal, vol. 15, núm. 6, IBFD, 2008, p. 318-320. 
Paz-Ares Rodríguez, Cándido, "La Infracapitalización. Una Aproximación Contractual”, Revista Derecho de Sociedades, núm. Extraordinario, 2004, p. 253-269.

Plitz, Detlev J., "General Report", en: AA.VV., Cahiers de Droit Fiscal International: International 1996, Aspects of Thin Capitalization, Congreso de Suiza, vol. 81b, 1996, p. 83-139, disponible en www.ibfd.org (IBFD - tax research platform).

Rohatgi, Roy, Idrovo, Juan Manuel (Trad.), Principios Básicos de Tributación Internacional, 1a edición en español, Legis, Bogotá D.C., 2008.

Rocha, Sergio André, Interpretation of Double Taxation Conventions. General Theory and Brazilian Perspective, Kluwer Law International BV, The Hague, 2009.

Sanz Gadea, Eduardo, Medidas Anti-elusión Fiscal, Documento IEF 08/09, Instituto de Estudios Fiscales, Madrid, 2009. Disponible en:

http://www.ief.es/documentos/recursos/publicaciones/documentos trabajo/20 09 08.pdf p. 27-31. [Consultada el 15 de mayo de 2011]

Villanueva Gutiérrez, Walker, "Conflictos de Calificación en los Convenios para Evitar la Doble Imposición", En García Novoa, Cesar y Hoyos Jiménez, Catalina (Coords). El tributo y su aplicación. Perspectivas para el siglo XXI, Tomo II, Marcial Pons, Buenos Aires, 2008, p. 1281-1301

Vogel, Klaus, On Double Taxations Conventions, Third edition, Kluwer Law International, Denveter, 1997. p. 31-32. núm. 56.

Xavier, Alberto, Derecho Tributario Internacional. Conceptos Fundamentales, Editorial Ábaco de Rodolfo de Palma, Buenos Aires, 2005.

Zielke, Rainer, Shareholder Debt Financing and Double Taxation in the OECD: An Empirical Survey with Recomendations for the Further Development of the OECD Model and International Tax Planning, Intertax, núm. 38, 2010. p. 62-92.

\section{Jurisprudencia y Contestaciones a las Consultas:}

Unión Europea, Tribunal de Justicia de la Unión Europea, Sala Gran Sala, Sentencia de 13 Mar. 2007, proc. C-524/2004, asunto Test Claimants in the Thin Cap Group Litigation. LA LEY 8926/2007.

Unión Europea, Tribunal de Justicia de la Unión Europea, Sala Primera, Sentencia de 14 de diciembre de 2006, proc. C-170/05, asunto Denkavit Francia [Disponible en: http://eur-lex.europa.eu]

Unión Europea, Tribunal de Justicia de la Unión Europea, Sala Quinta, Sentencia de 12 Dic. 2002, proc. C-324/2000, asunto Lankhorst-Hoborst. LA LEY 209152/2002

Tribunal Supremo, Sala Tercera, de lo Contencioso-administrativo, Sección 2aa Sentencia de 6 Abr. 2011, rec. 103/2007. LA LEY 14493/2011.

Tribunal Supremo, Sala Tercera, de lo Contencioso-administrativo, Sección 2aa Sentencia de 17 Mar. 2011, rec. 5871/2006. LA LEY 14311/2011. 
Tribunal Supremo, Sala Tercera, de lo Contencioso-administrativo, Sección 2a Sentencia de 1 Oct. 2009, rec. 1596/2004. LA LEY 237382/2009.

Tribunal Supremo, Sala Tercera, de lo Contencioso-administrativo, Sección 2a Sentencia de 21 Feb. 2008, rec. 8310/2002. LA LEY 8984/2008

Tribunal Supremo, Sala Tercera, de lo Contencioso-administrativo, Sección 2ạ , S de 11 Feb. 2000, rec. 25/1999. LA LEY 35806/2000.

Audiencia Nacional, Sala de lo Contencioso-administrativo, Sección 2ª , Sentencia de 5 Nov. 2009, rec. 169/2006. LA LEY 210244/2009.

Audiencia Nacional, Sala de lo Contencioso-administrativo, Sección 7ạ, Sentencia de 23 Abr. 2007, № de Recurso: 295/2006. LA LEY 12703/2007

Audiencia Nacional, Sala de lo Contencioso-administrativo, Sección 7ạ, Sentencia de 9 Oct. 2006, rec. 109/2006. LA LEY 124963/2006

Audiencia Nacional, Sala de lo Contencioso-administrativo, Sección 5ă , Sentencia de 15 Ene. 2004, rec. 626/2002

Tribunal Económico-Administrativo Central, Sección Vocalía 10ạ, Resolución de 25 Jun. 2009, rec. 656/2007. LA LEY 184069/2009

Dirección General del Tributo, Subdirección General de Impuestos sobre las Personas Jurídicas, Consulta vinculante V1859-06, de 19 de septiembre de 2006 de 2006. LA LEY $2607 / 2006$.

Dirección General del Tributo, Subdirección General de Impuestos sobre las Personas Jurídicas, Consulta general 2476-03, de 26 de diciembre de 2003. LA LEY 2738/2003.

Dirección General del Tributo, Subdirección General de Impuestos sobre la Renta de las Personas Jurídicas, Consulta General, No. 1210 de 20 de junio de 2001, LA LEY $1361 / 2001$.

Dirección General del Tributo, SG de Impuestos sobre las Personas Jurídicas, Consulta Vinculante No. 0503 de 30 de marzo de 1998. Disponible en: http://petete.minhac.es/Scripts/know3.exe/tributos/consulta/texto.htm?Consult a=.EN+Normativa+(Ley)\&Pos=3658 [Consultada el 15 de mayo de 2011] 


\section{Colección de Documentos de Trabajo del IELAT}

DT 1: Jaime E. Rodríguez O., México, Estados Unidos y los Países Hispanoamericanos. Una visión comparativa de la independencia. Mayo 2008.

DT 2: Ramón Casilda Béjar, Remesas y Bancarización en Iberoamérica. Octubre 2008.

DT 3: Fernando Groisman, Segregación residencial socioeconómica en Argentina durante la recuperación económica (2002 - 2007). F. Abril 2009

DT 4: Eli Diniz, El post-consenso de Washington: globalización, estado y gobernabilidad reexaminados. Junio 2009.

DT 5: Leopoldo Laborda Catillo, Justo de Jorge Moreno y Elio Rafael De Zuani, Externalidades dinámicas y crecimiento endógeno. Análisis de la flexibilidad de la empresa industrial español. Julio 2009

DT 6: Pablo de San Román, Conflicto político y reforma estructural: la experiencia del desarrollismo en Argentina durante la presidencia de Frondizi (1958 - 1962).

Septiembre 2009

DT 7: José L. Machinea, La crisis financiera y su impacto en America Latina. Octubre 2009.

DT 8: Arnulfo R. Gómez, Las relaciones económicas México- España (1977-2008). Noviembre 2009.

DT 9: José Lázaro, Las relaciones económicas Cuba- España (1990-2008). Diciembre 2009.

DT 10: Pablo Gerchunoff, Circulando en el laberinto: la economía argentina entre la depresión y la guerra (1929-1939). Enero 2010.

DT 11: Jaime Aristy-Escuder, Impacto de la inmigración haitiana sobre el mercado laboral y las finanzas públicas de la República Dominicana. Febrero 2010.

DT 12: Eva Sanz Jara, La crisis del indigenismo mexicano: antropólogos críticos y asociaciones indígenas (1968 - 1994). Marzo 2010.

DT 13: Joaquín Varela, El constitucionalismo español en su contexto comparado. Abril 2010. 
DT 14: Justo de Jorge Moreno, Leopoldo Laborda y Daniel Sotelsek, Productivity growth and international openness: Evidence from Latin American countries 19802006. Mayo 2010.

DT 15: José Luis Machinea y Guido Zack, Progresos y falencias de América Latina en los años previos a la crisis. Junio 2010.

DT 16: Inmaculada Simón Ruiz, Apuntes sobre historiografía y técnicas de investigación en la historia ambiental mexicana. Julio 2010.

DT 17: Julián Isaías Rodríguez, Belín Vázquez y Ligia Berbesi de Salazar, Independencia y formación del Estado en Venezuela. Agosto 2010.

DT 18: Juan Pablo Arroyo Ortiz, El presidencialismo autoritario y el partido de Estado en la transición a la economía de libre mercado. Septiembre 2010.

DT 19: Lorena Vásquez González, Asociacionismo en América Latina. Una Aproximación. Octubre 2010.

DT 20: Magdalena Díaz Hernández, Anversos y reversos: Estados Unidos y México, fronteras socio-culturales en La Democracia en América de Alexis de Tocqueville. Noviembre de 2010.

DT 21: Antonio Ruiz Caballero, iAbre los ojos, pueblo americano! La música hacia el fin del orden colonial en Nueva España. Diciembre de 2010.

DT 22: Klaus Schmidt- Hebbel, Macroeconomic Regimes, Policies, and Outcomes in the World. Enero de 2011

DT 23: Susanne Gratius, Günther Maihold y Álvaro Aguillo Fidalgo. Alcances, límites y retos de la diplomacia de Cumbres europeo-latinoamericanas. Febrero de 2011.

DT 24: Daniel Díaz- Fuentes y Julio Revuelta, Crecimiento, gasto público y Estado de Bienestar en América Latina durante el último medio siglo. Marzo de 2011.

DT 25: Vanesa Ubeira Salim, El potencial argentino para la producción de biodiésel a partir de soja y su impacto en el bienestar social. Abril de 2011.

DT 26: Hernán Núñez Rocha, La solución de diferencias en el seno de la OMC en materia de propiedad intelectual. Mayo de 2011. 
DT 27: Itxaso Arias Arana, Jhonny Peralta Espinosa y Juan Carlos Lago, La intrahistoria de las comunidades indígenas de Chiapas a través de los relatos de la experiencia en el marco de los procesos migratorios. Junio 2011.

DT 28: Angélica Becerra, Mercedes Burguillo, Concepción Carrasco, Alicia Gil, Lorena Vásquez y Guido Zack, Seminario Migraciones y Fronteras. Julio 2011.

DT 29: Pablo Rubio Apiolaza, Régimen autoritario y derecha civil: El caso de Chile, 19731983. Agosto 2011.

DT 30: Diego Azqueta, Carlos A. Melo y Alejandro Yáñez, Clean Development Mechanism Projects in Latin America: Beyond reducing CO2 (e) emissions. A case study in Chile. Septiembre 2011.

DT 31: Pablo de San Román, Los militares y la idea de progreso: la utopía modernizadora de la revolución argentina (1966-1971). Octubre 2011.

DT 32: José Manuel Azcona, Metodología estructural militar de la represión en la Argentina de la dictadura (1973-1983). Noviembre 2011.

DT 33: María Dolores Almazán Ramos, El discurso universitario a ambos lados del Atlántico. Diciembre 2011.

DT 34: José Manuel Castro Arango, La cláusula antisubcapitalización española: problemas actuales. Enero 2012. 
Todas las publicaciones están disponibles en la página Web del Instituto: www.ielat.es

(C) Instituto de Estudios Latinoamericanos (IELAT)

Los documentos de trabajo que IELAT desarrolla contienen información analítica sobre distintos temas y son elaborados por diferentes miembros del Instituto $u$ otros profesionales colaboradores del mismo. Cada uno de ellos ha sido seleccionado y editado por el IELAT tras ser aprobado por la Comisión Académica correspondiente.

Desde el IELAT animamos a que estos documentos se utilicen y distribuyan con fines académicos indicando siempre la fuente. La información e interpretación contenida en los documentos son de exclusiva responsabilidad del autor y no necesariamente reflejan las opiniones del IELAT.

Instituto de Estudios Latinoamericanos

Colegio de Trinitarios

P.V.P.: $20 €$

C/Trinidad 1 - 28801

Alcalá de Henares (Madrid)

Con la colaboración de:

España

$34-918852579$

ielat@uah.es

S Santander

www.ielat.es

UNIVERSIDADES 